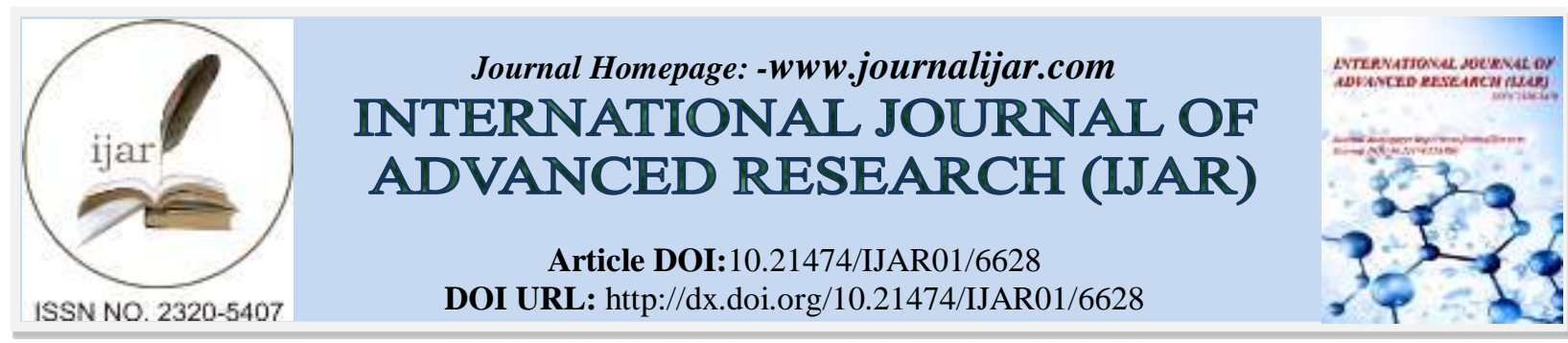

RESEARCH ARTICLE

\title{
DETERMINATION AND INCIDENCE OF PERSISTENT FINGER JOINT PAIN AMONG MALE COLLEGE STUDENTS DUE TO MOBILE PHONES OVERUSE.
}

\section{Ahmed Abdelmoniem Ibrahim ${ }^{1}$, Mohamed raffat Mohamed atteya ${ }^{2}$, Ehab Mohamed Kamel ${ }^{2}$, Hamad Fahad hamad alshammri ${ }^{2}$ and Abdulaziz Saud Abdulaziz Al-shaya ${ }^{2}$.}

1. Ph D. PT Physiotherapy Department, Cairo university hospitals, Cairo; Egypt pox -11562.

2. Ph. D. PT Physical Therapy Department, College of Applied medical sciences, University of Hail-KSA pox.

\section{Manuscript Info}

(..........................

Manuscript History

Received: 24 December 2017

Final Accepted: 26 January 2018

Published: February 2018

Keywords:-

Finger Pain, Dominant Hand,

Smartphones.

\section{Abstract}

Background: Smart devices is the language of modern society and There are some health concerns associated with these technology, Design: cross sectional study

Method: The measurement of grip and pinch strength grip was taken by dynamometer (hydraulic hand dynamometer) and the measures of pinch strength was by pinch gauge. Result: People who have been continuously using their smart devices more than 10 years have a significant decrease in the strength of both grip and pinch compared to those who use it less.

Conclusion: Related to the kind of Handedness, the dominant side grip strength is more than non-dominant side grip strength. There is relationship between the duration of usage smart phone and grip, pinch strength.

Copy Right, IJAR, 2018,. All rights reserved.

\section{Introduction:-}

Cell phones are one such technology. Socially and culturally we are dealing with constant interconnectedness which may be good or bad as well as inconsiderate users who feel they should talk wherever they are regardless of the people around them. But this isn't about etiquette. This is about ergonomics. (1) The cell phone has led to some health conditions, but it wasn't until the invention of a supporting technologies: mobile data, cellular email and the almighty text message; that the repetitive stress became a real problem for most users. Text messages have some great advantages and have changed our culture. But the input method leaves a lot to be desired. Texting Thumb is a repetitive stress injury that affects the thumb and wrist. Pain and sometimes a popping sound are present on the outside of the thumb at or near the wrist. There can also be a decrease in grip strength or range of motion.

Cell phones are an indispensible tool in today's society. However, there are some health concerns associated with these tiny pieces of technology. We can spend hours with a phone in our grasp, whether we are talking or texting, and not think twice about what it is doing to our hands. Some of the most common conditions caused by too much cell phone use are trigger finger and 'text thumbs' . smart phone user may complains about Uncomfortable pain even if not sever. (2)

BlackBerry thumb is neologism that refers to a form of repetitive strain injury (RSI) caused by the frequent use of the thumb to press buttons on smart phones, or other mobile devices. The name of the condition comes from the Blackberry, a brand of smartphone debuted in1999. (3) 
The medical name for the condition is De Quervain's syndrome and is associated with the tendons connected to the thumb through the wrist. Causes for the condition extend beyond smart phones and gaming consoles to include activities like golf, racket sports, and lifting. (4)

Work-related musculoskeletal disorders (WMSDs) of the upper extremities (UE) are common and potentially disabling, yet preventable. WMSDs comprise a heterogeneous group of diagnoses which include numerous specificclinical entities, including disorders of the muscles, tendons and tendon sheaths, nerve entrapment syndromes, joint disorders, and neurovascular disorders. In 1994, 332,000 musculoskeletal disorders due to repeated trauma were reported in United States workplaces, representing nearly $65 \%$ of the occupational disease cases . (4)

The popularity of text messaging or SMS on mobile phones has given rise to a new injury called text Messaging injury .TMI is a form of Repetitive strain injury (RSI) which is described by pain associated with loss of function in a limb resulting from repetitive movement or sustained static loading. TMI is normally caused by overuse of thumb during text messaging on mobile phone. Besides TMI, there are other terms, such as Blackberry thumb and Gamers thumb, to describe RSI related to wire-less hand held and video games devices. The research into the effects of text messaging on the thumb and related fingers has been limited. Most RSI research concentrated on computers since keyboard users or office workers have been identified to have high levels of job discomfort. It has been found that upper extremity musculoskeletal disorder, such as carpal tunnel syndrome CTS are associated with computer keyboard usage . factors contributing to CTS and job discomfort were found to be related to speed and force of keyboard operation. Text messaging usually involves the use of thumb of one hand to type on phone keypad.

The movement of the thumb covers motion in planes of flexion - extension, abduction -adduction and opposition . these motions occur simultaneously in three dimensions and as a result, it is difficult to determine the kinematics of the thumb. Measurements of thumb motion have been made in earlier researches using marker based optical motion capture system, goniometry and fluoroscopy. TMI is affecting more and more children and young adult due to excessive text messaging . the objective of the study was to determine the thumb motion and typing forces on keypad of mobile phone during text messaging. (5)

The hands are essential for most occupational and daily living activities. Pain and loss of hand movement-related functions decrease the patient's ability toperform manual tasks and diminishes the patient's quality of life. (6-8) Women are more vulnerable than men to the effects of hand problems on their daily activities. (7)

The prevalence of hand pain in the general population varies between $12 \%$ and $32 \%$. (7-8) Depending on the definition of the symptoms (severity and duration). The prevalence of hand pain seems to increase with age. (10-12)

The incidence of hand pain was $22 \%$ among a group of older adults, and women reported higher incident hand pain than men, with little influence of age on hand pain . (8)

Among the other risk factors that may contribute to hand pain are occupational loading and overuse of the hand . (13-14)

The biomechanical factors related to the differential use of the hands and their joints may also play a role in the development of pain, The forces generated by diverse hand activities produce different loads on the finger joints. A biomechanical analysis of finger joint load showed that fine pinch grip resulted in greater loads than power grip. (15)

Previously, we have shown that pain is more common in the right than the left hand, in the thumb, index, and middle fingers comparedwith the little finger, and in the inter phalangeal (IP) joints compared with the metacarpo phalangeal (MCP) joints . (16)

\section{Objectives:-}

the purposes of this study was determine if there is effect of prolonged use of smartphone on hand grip strength and pinch strength and the pain related to overusing of phones. This study aimed at students of the University of Hail. 


\section{Methodology:-}

Subjects:-

Inclusion criteria:-

This study was conducted to120 students from Hail university in KSA participated from various departments aged between 18-27.

\section{Exclusion criteria:-}

Cases having past history of fracture or intractable disease of hand and general weakness were removed from this study .

\section{Procedure:-}

Type of handedness determination and the Time from Using smart phones was conducted through questionnaire which consisted of a total 16 question items. Grip and pinch strength was measured with dynamometer (hydraulic hand dynamometer ), pinch strength was measured using pinch gauge (pinch gauge ) and assesse pain by numeric scale .The subjects were seated with their knee flexed $90^{\circ}$ and back rested on chair, shoulder adducted and neutrally rotated, elbow flexed at $90^{\circ}$, forearm in neutral position, and wrist 0-20 flexion. The thenar group of muscle is rested on the handle of hand dynamometer.

For each strength test the scores of three successive trials were recorded for each hand .

\section{Equipments:-}

The standard, adjustable-handle dynamometer, reported as the most accurate for measuring grip strength, was used. For standardization, it was set at the second handle position for all subjects. The dynamometer was lightly held around the readout dial by the examiner to prevent inadvertent dropping. The pinch gauge, used to measure key pinch was held by the examiner at the distal end to prevent dropping. Scores were read on the needle side of the red readout marker. The calibration of both instruments was tested periodically during the study.

\section{Data analysis:-}

SPSS version 16 was used for data analysis. Descriptive data was calculated, The percentage of type of dominant hand, grip and pinch strength for both right and left hand and pain scale.

\section{Results:-}

Table 1:- Duration of usage:

\begin{tabular}{|l|l|}
\hline Group 1 & $1-2$ years \\
\hline Group 2 & $3-4$ years \\
\hline Group 3 & $5-6$ years \\
\hline Group 4 & $7-9$ years \\
\hline Group 5 & Up to 10 years \\
\hline
\end{tabular}

Table 2:- (Right handiness)

\begin{tabular}{|c|c|c|c|c|c|}
\hline Right handiness & $\begin{array}{c}\text { Group } \\
\mathbf{1}\end{array}$ & Group 2 & Group 3 & $\begin{array}{c}\text { Group } \\
\mathbf{4}\end{array}$ & $\begin{array}{c}\text { Group } \\
\mathbf{5}\end{array}$ \\
\hline Time to use phone & $\% 5.13$ & $\% 32.48$ & $\% 35.04$ & $\% 11.97$ & $\% 3.42$ \\
\hline Right grip strength & $\% 7.69$ & $\% 13.68$ & $\% 17.95$ & $\% 47.01$ & $\% 1.71$ \\
\hline Left grip strength & $\% 28.21$ & $\% 32.48$ & $\% 11.11$ & $\% 16.24$ & $\% 0.00$ \\
\hline Right pinch strength & $\% 2.56$ & $\% 3.42$ & $\% 55.56$ & $\% 24.79$ & $\% 0.85$ \\
\hline Left pinch strength & $\% 15.38$ & $\% 54.70$ & $\% 15.38$ & $\% 1.71$ & $\% 0.00$ \\
\hline Presence of Pain & $\% 14.53$ & $\% 51.28$ & $\% 6.84$ & $\% 5.98$ & $\% 3.42$ \\
\hline
\end{tabular}


Fig 1:- Right handiness

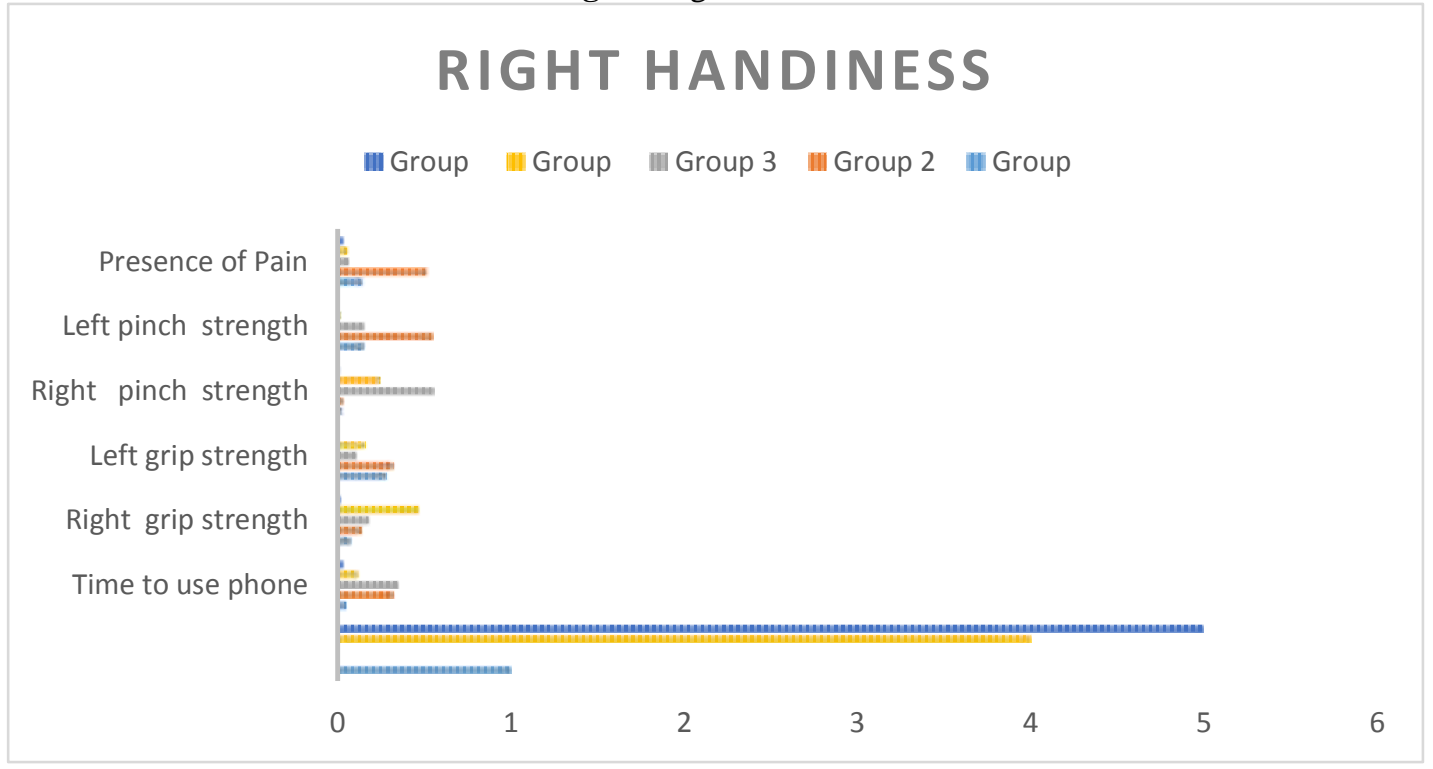

Table 3:- (Left handiness )

\begin{tabular}{|c|c|c|c|c|c|}
\hline Left handiness & $\begin{array}{c}\text { Group } \\
1 \\
\end{array}$ & $\begin{array}{c}\text { Group } \\
2 \\
\end{array}$ & Group 3 & $\begin{array}{c}\text { Group } \\
\mathbf{4} \\
\end{array}$ & $\begin{array}{c}\text { Group } \\
5 \\
\end{array}$ \\
\hline Time to use phone & $\% 3.4$ & $\% 1.7$ & $\% 5.1$ & $\%$ & $\% 12$ \\
\hline Right grip strength & $\% 3.4$ & $\% 4.3$ & $\%$ & $\% \quad 0.9$ & $\% 11.1$ \\
\hline Left grip strength & $\% 1.7$ & $\% 2.6$ & $\%$ & $\% 3.4$ & $\% 0.9$ \\
\hline Right pinch strength & $\% 5.1$ & $\% 0.9$ & $\%$ & $\% 4.3$ & $\% 0.9$ \\
\hline Left pinch strength & $\% 4.3$ & $\% 2.6$ & $\%$ & $\% 3.4$ & $\% 0.00$ \\
\hline Presence of Pain & $\% 2.6$ & $\% 2.6$ & $\%$ & $\% 2.6$ & $\% 12$ \\
\hline
\end{tabular}

Fig 2:- Left handiness

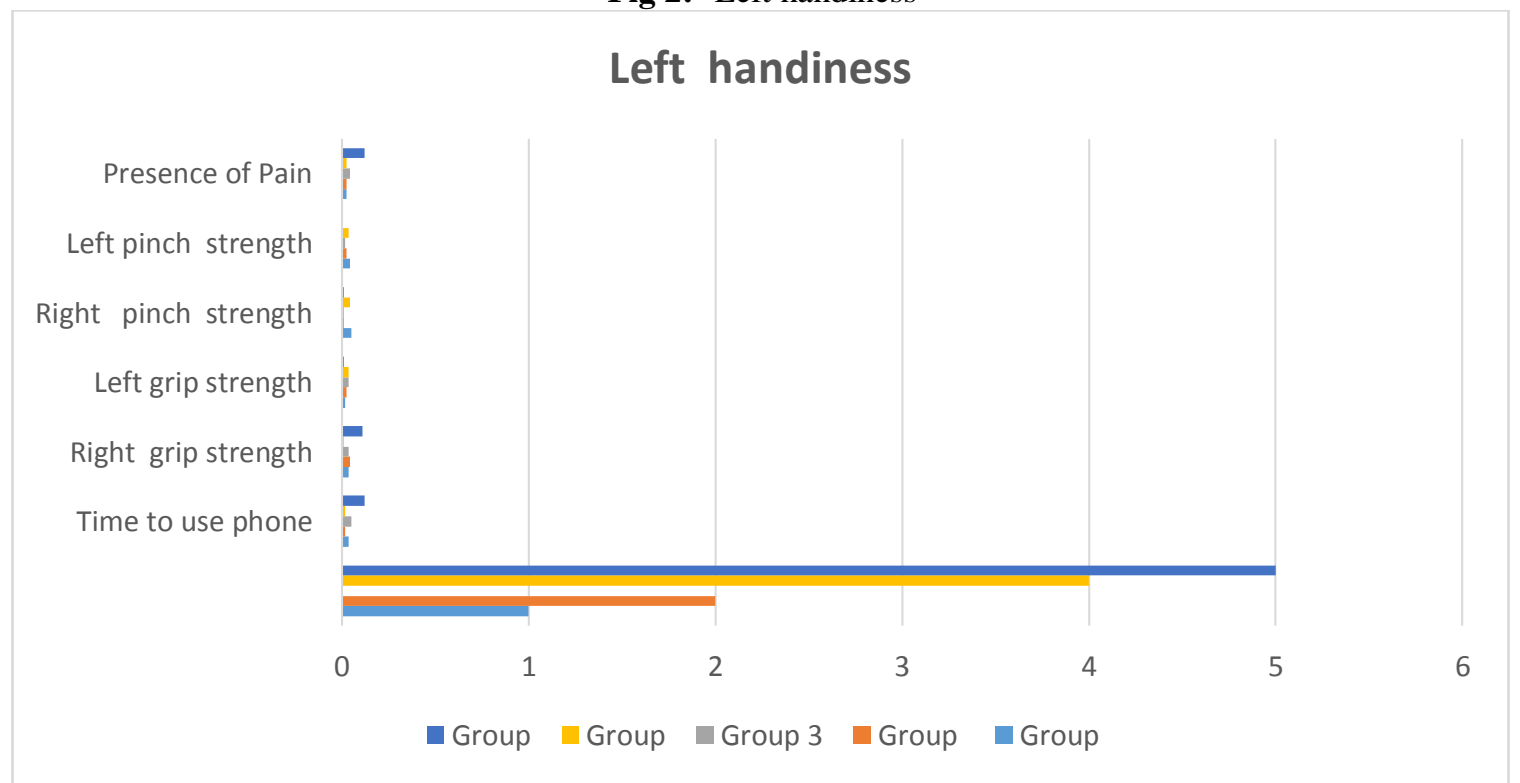

In Right Handedness:-

Highest score of Right grip is $47.01 \%$ is $56-70$ pounds

Highest score of Right pinch is $55.56 \%$ up to 12 pounds 
Highest score of Left grip is $32.48 \% 26-40$ pounds

Highest score of Left pinch is $54.70 \%$ 6-8 pounds

\section{In Left Handedness:-}

Highest score of Left grip is $6.8 \%$ represent $41-70$ pounds

Highest score of Left pinch is $4.3 \%$ represent 3-5 pounds

Highest score of Right grip is $11.1 \%$ represent up to 70 pounds

Highest score of Right pinch is 5.1\% 3-5 pounds

\section{Discussion:-}

Readings in correspondence with duration of usage graph -1:-

People who have used of smart devices for more than 10 years have a significant decrease in the strength of the grip and pinch both compared to those who use it less. The rate of pain in this group is from 3-5 regarding to numeric rating scale and termed as mild to moderate pain. Followed by groups of 3-4 and 5-6 years which were somewhat similar in readings.

The first group from 1-2 years recorded the highest readings, which is the normal range for the strength grip and pinch both .

\section{Related to the kind of Handedness graph -2:-}

in this study show people how right-handedness and grip pinch is more powerful compared to those who have lefthandedness,

but can cause a number of $\mathrm{R}$ handedness in this study represent 105 and $\mathrm{L}$ handedness 15 subject only may helped in the incorrect judgment.

Generally, the dominant side grip strength is more strong than non- dominant side grip strength . (19)

There are a dominant side hand have 30\% more strong than a non-dominant side hand but normally it is strong about $5-10 \%$. there are a dominant side have 5-7\% more strong grip and pinch than a non- dominant side hand in the type of right hand. there are not difference in the type of left hand Be very aware of stiffness, sharp pain or dull ache, numbness or tingling, or poor grip, which may come on after a heavy session on the computer using either the keyboard or the mouse, or when using a pen, or with thumb movements when using a Games Console, or when texting on a mobile phone. (20-21)

Try to take breaks between hand activities, of a few minutes each half-hour or ten minutes each hour. Massage your hands and arms to restore the circulation and refresh the muscles and tendons. Flex your fingers, and stretch your arms out to the side, above your head, then to your sides, keeping your spine straight. This applies at home or at school - if possible Do warm up exercises the same as when you do before. Gentle exercise can only help.

\section{Conclusion:-}

We conclude from this study Increased the duration of using of smart devices reduces the grip and pinch strength . Strength of Dominant hand is more than that of Non-dominant hand .

\section{Limitations \& Suggestions:-}

\section{Recommendations;-}

Checklist for Mobile Using Be aware that by using a mobile phone and holding it in one hand, with that hand in a claw position, and when moving the thumb rapidly over the keypad, puts an enormous strain on tendons in the hand and arm.

In between, massage your hand and thumb, and rotate your hands at the wrists, in clockwise and anticlockwise directions. If it already hurts to text, use the fingers of the other hand or the end of a pen to press the keypad, reduce using your phone, and get medical help.

Keep a diary of any aches and pains, and when, and for how long you use the equipment. 
But remember - prevention is better than cure - you only have one body \& one life.

\section{For Future Researchers:=}

Use a larger segment of participants, both males and females and compare between them from different ages. and record the most important differences. And record other combination of differences including examination of various pinches and grasps.

\section{Limitations:-}

Due to lack of awareness regarding proper physiotherapy techniques which can avoid the repetitive strain injury RSI the number of participants in this study were 120 only .

\section{References:-}

1. September 22, 2010 By Administratormike, guide-for-young-people-how-to-avoid-rsi

2. Nett MP, Collins MS, Sperling JW (2008). "Magnetic resonance imaging of acute "wiiitis" of the upper extremity". Skeletal Radiology 37 (5): 481-83. Doi:10.1007/s00256-008-0456-1. PMID 18259743(2008)

3. Mayo Clinic Staff (01 August 2012). "De Quervain's Tenosynovitis".3* Mayo Clinic. Retrieved 2012-12-05(2012).

4. Evaluation and Management of Chronic Work-Related Musculoskeletal Disorders of the Distal Upper Extremity George Piligian, MD, MPH,1_Robin Herbert, MD,1 Michael Hearns, MD,2

5. Jonathan Dropkin, MS, PT,1 Paul Landsbergis, EdD, MPH,1,3 and Martin Cherniack, MD, MPH reported to the Bureau of Labor Statistics [BLS, (1997).(

6. Thumb motion and typing forces during text messaging on a mobile phone F.R ong

7. School of mechanical and manufacturing Engineering ,Singapore polytechnic, Singapore (2010)

8. Spacek E, Poiraudeau S, Fayad F, Lefevre-Colau MM, Beaudreuil( J, Rannou F, et al. Disability induced by hand osteoarthritis: are patients with more symptoms at digits 2-5 interphalangeal joints different from those with more symptoms at the base of the thumb? Osteoarthritis Cartilage 2004 12:366-73(2004).

9. Cimmino MA, Sarzi-Puttini P, Scarpa R, Caporali R, Parazzini( F, Zaninelli A, et al. Clinical presentation of osteoarthritis in general practice: determinants of pain in Italian patients in the AMICA study. Semin Arthritis Rheum 2005;35:17-23(2005).

10. Thomas E, Croft PR, Dziedzic KS. Hand problems in community( dwelling older adults: onset and effect on global physical function over a 3-year period. Rheumatology (Oxford) 2009 7-48:138(2009)

11. Grotle M, Hagen KB, Natvig B, Dahl FA, Kvien TK. Prevalence( and burden of osteoarthritis: results from a population survey in Norway. J Rheumatol 2008;35:677-84(2008) 27

12. Urwin M, Symmons D, Allison T, Brammah T, Busby H, Roxby M, et al. Estimating the burden of musculoskeletal disorders in the community: the comparative prevalence of symptoms at different anatomical sites, and the relation tosocial deprivation. Ann Rheum Dis 1998;57:649-55(1998)

13. Jones G, Cooley HM, Bellamy N. A cross-sectional study of the association between Heberden's nodes, radiographic osteoarthritis of the hands, grip strength, disability and pain. Osteoarthritis

14. Cartilage 2001;9:606-11(2001).

15. Wilder FV, Barrett JP, Farina EJ. Joint-specific prevalence of osteoarthritis of the hand. Osteoarthritis Cartilage 2006;14 7-935(2006):

16. Helliwell PS, Mumford DB, Smeathers JE, Wright V. Work related upper limb disorder: the relationship between pain, cumulative load, disability, and psychological factors. Ann Rheum Dis 1992;5:1325-9(1992)

17. Hayes M, Cockrell D, Smith DR. A systematic review of musculoskeletal( disorders among dental professionals. Int J Dent Hyg 2009;7:159-65(2009).

18. Radin EL, Parker HG, Pull IL. Pattern of degenerative arthritis preferential involvement of the distal finger joints. Lancet 1971;1:377-9(2009).

19. ding H, Solovieva S, Vehmas T, Riihimaki H, Leino-Arjas Finger joint pain in relation to radiographic osteoarthritis and joint location: a study of middle-aged female dentists and teachers. Rheumatology (Oxford) 2007;46:15025(2007).

20. kraft GH. Detels PE: Position of (unction of wrist. Arch Phys Med Rehabil 53:272-275. (1972)

21. Lunde BK. Brewer WD, Garcia PA: Grip strength of college women. Arch Phys Med Rehabil 53:491-493.(1972)

22. Mathiowetz V. Weber K, Volland G. Kashman N: Reliability and validity of hand strength evaluation. J Hand Surg 9A:222- (1994)

23. (20) pryce JC: Wrist position between neutral and ulnar deviation that facilitates maximum power grip strength. J Biomechanics(1994)

24. kirkpatrick JE: Evaluation of grip loss. Calif Med 95:314-320 (1956). 